sciendo Порівняльна професійна педагогіка 8(3)/2018 Comparative Professional Pedagogy 8(3)/2018

DOI: $10.2478 /$ rpp-2018-0041

$\mathrm{PhD}$, Assistant Professor, ARIF SHALA

Professional Development Institute-PDI, Address: Mother Theresa St. n. n, Prishtina, 10000, Kosovo E-mail: Shala.arif@pdi-ks.org

$\mathrm{PhD}$, Assistant Professor, BEKIM BALIQI Department of Political Science, University of Prishtina, Address: 31 George Bush St., Prishtina, 10000, Kosovo E-mail: bekim.baliqi@uni-pr.edu

\title{
LEADERSHIP DEVELOPMENT AMONG UNIVERSITIES IN KOSOVO: CHALLENGES AND ALTERNATIVES
}

\begin{abstract}
This article analyses the potential impact of leadership development initiatives on the quality of higher education institutions in Kosovo. Taking into account the fact that leadership is a crucial factor in improving management and performance of institutions, it is necessary to develop and integrate it into the higher education system. Current developments in the education have proven that leadership development in universities is no longer an option, it is instead a necessity. This development takes place at the beginning of teachers' carrier and aims to assist them in developing leadership skills they need to lead schools in the future. School leaders who are considered to be successful at leading tend to make sure that their staff have access to workplace learning and training with many schools providing sets of professional learning activities which ensure the development of leadership skills. This approach emphasises tasks related with student achievements, staff performance, curriculum development and data analysis. It has been defined that the development of leadership that rests on organisation theory is hindered by numerous current challenges at the universities in Kosovo. These challenges are: lack of networking and cooperation, lack of planning and, ultimately, the lack of management and leadership skills. While higher education institutions in Kosovo face many challenges, we assume that they could enhance academic quality and overall student achievements by increasing leadership capacities. In the context of transition of the university role, the demand for leadership development is a need for carrying out university reforms and achieving educational advancement. Thus, the development of leadership skills is more a necessity than an option for higher education institutions to prepare students appropriately for the new era. It has been substantiated that practices such as multisource feedback, action learning and coaching have proven to be useful and their application could increase leadership capacities of educational institutions that are built on organisational approaches and theories concerning enhancement of their quality.

Keywords: leadership development, universities, Kosovo, education reforms.
\end{abstract}

\section{INTRODUCTION}

Higher educational institutions have essentially three key and interrelated functions: knowledge function, marketplace function, and socio-political function. In the context of both globalisation and the transition of the university role, the demand for leadership 
sciendo Порівняльна професійна педагогіка 8(3)/2018

Comparative Professional Pedagogy 8(3)/2018

development is a need to drive university reforms and to achieve improvement of the education system. Leadership capacities are of crucial importance when it comes to assuming the new roles of the universities in the increasingly competitive and more demanding era. Moreover, current developments across the world demand a new role for these institutions, one that significantly relies on the leadership capacities of the management and academic staff.

The construct of an 'organisation' is characteristic in the modern period and subsequently is inseparable from the domain of education. Nowadays, education systems have become the subject of transformations, and as such request efficiency and higher performance. Consequently, defining and understanding the organisation within educational settings is crucial. Scholars have revealed that student achievement is affected by teaching and university leadership. Furthermore, literature also implies that education institutions which have positively influenced student achievement tend to have university management that is adjusted to the needs of the staff concerning continuous learning and effective leadership development.

The need for leadership development within higher education institutions goes hand in hand with their ever-increasing responsibility. Nowadays higher education institutions have responsibilities that go beyond administrative and managerial duties, such as budgeting, research and community projects, curriculum development, policy analyses and leadership development. The challenge is currently to identify practical approaches for developing such leadership skills.

When studying concepts of leadership one does not only come across different approaches to leadership but also finds a significant amount of literature devoted to leadership development. As institutions attribute an essential role to their leaders and perceive the learning of leadership skills as difficult and complicated, they invest significant time and money into their development (Riggio, 2008). It implies that leadership is necessary because leaders are not born but made. In his review on leadership development D. Day (2000) points out that leadership is usually viewed as an individual-level skill. The inspirational leadership approach, for example, is based on the assumption that the personal qualities or charisma of leaders are influencing their behaviour and success (Bass, 1994; Mullins, 2007).

Leadership skills are even more important for leaders in educational institutions as they have multifaceted job responsibilities. Therefore, school leaders have three domains of functioning:

- macro level (they work with governments and agencies);

- middle-level (the leader focuses on promoting a specific educational organisation);

- micro level (leaders generally focus on effective management of educational organisations).

In addition to different job responsibilities, leaders are strained by ever-changing context and environments, which acquire even more vital leadership skills. Recent developments have reshaped the approach to the professional identity of teachers, and the impact on individual performance has driven teachers to give in to the pressure to conform to the organisational culture, as they attempt to link their professionalism to such expectations. The challenge of educational institutions is to practice leadership correctly since literature suggests that inappropriate leadership practices often lead to conflict within the staff, resistance and, often, favouritism towards specific members of the staff (Yukl, 2006). The performance and achievement of the universities are strongly dependent on leadership development literature and the proper practices of leadership theories and approaches. 


\section{THE AIM OF THE STUDY}

This paper outlines possible approaches that could lead to effective leadership within educational organisations and leadership development related to student achievements, staff performance, curriculum development and overall quality assurance of higher educational institutions. Further, analysis of leadership development provides both theoretical and practical opportunities for higher education management in Kosovo to integrate and advance leadership in these institutions. Moreover, it allows evaluating existing practices and enhancing professional qualification in this study field.

\section{THEORETICAL FRAMEWORK AND RESEARCH METHODS}

Many scholars differentiate different kinds of interventions for developing the skills. The most common interventions are in the form of formal training, developmental activities or self-help activities (Yukl, 2006). Formal training takes place as workshops or management courses at the university and offered by professional trainers. In contrast, the developmental activities are undertaken during the daily work, embedded in the operational job assignments. They include, for example, mentoring by a more experienced person, coaching or individual assignments designed to improve relevant skills. Self-help activities do not require the support of a third party but can be done by the leaders themselves. Reading books, such as the above mentioned, or participating in e-learning programs are two typical examples. The paper will describe in more details development tools which organisations often use: $360^{\circ}$ Feedback, coaching, and action learning.

In multisource feedback, 360-degree feedback or multi-rater feedback program (all terms are used interchangeably) managers receive information about their being perceived by different groups of people with whom they regularly interact (Atwater, \& Brett, 2005). It includes ratings of the leader's subordinates, peers, bosses, and clients as well as self-rating part (Seifert et al., 2003). The main idea behind the integration of multiple sources in the feedback process is that the behaviour of leaders changes depending on the context and the situation they are acting in (Day, 2000). Usually, multisource feedback consists of ratings on specific types of behaviour skills and is provided in a report, which contains descriptive information as well as the graphical presentation of the data (Seifert et al., 2003).

The multisource feedback gives, on the one hand, an entirely accurate picture of the leader's performance (Day, 2000) and on the other hand, leaders can gain a more comprehensive perspective of their work performance (Yammarino \& Atwater, 1993). It is, therefore, a useful development tool for building intrapersonal competence while providing important leader self-knowledge, self-understanding and self-awareness (Barney \& Hansen, 1994). Additionally, feedback that includes ratings of peers and superiors is given more attention by the leaders, and they are more likely to show their competences afterwards (London, \& Smither, 1995). Despite the ever-growing usage and importance of the multi-source feedback for the development of leadership skills, one has to keep in mind the disadvantages of that method. The report of the 360-degree feedback contains a vast amount of information, which might be overwhelming for the feedback recipient. It occurs primarily when no feedback facilitators are available and when there is a lack of guidance in the organisation concerning the individual change process. It is moreover recommended to check the effectiveness and efficiency as well as the invested amount of time and effort (Day, 2000).

Coaching is an ongoing process of leadership development (Day, 2000). It is a form of face to face learning and behavioural change (Peterson, 1996). Its objectives constitute of improving individual performance of leaders in an attempt to increase their effectiveness 
sciendo Порівняльна професійна педагогіка 8(3)/2018

Comparative Professional Pedagogy 8(3)/2018

within the organisation (Kilburg, 1996). Coaching is used to train a specific leader for a specific skill or help him/her overcome a specific problem (Day, 2000; Day, \& Halpin, 2001). In most cases, coaching is a useful practice since it provides a leader with suggestions regarding specific challenges, such as how to work with people from different countries, how to respond to a demanding supervisor and many other types, as well as unique issues in the work environment. The leader who is assigned a coach has significant advantage of receiving specific suggestions and feedback from someone who understands the challenges while enjoying confidentiality (Yukl, 2006). Despite its benefits, coaching is a costly training practice for companies; therefore, it is not a surprise that companies try to keep this as short as possible and as specific as it can be.

Action learning is another approach which is becoming more popular among companies. It has become rather apparent to many organisations that it is not possible to train and prepare leaders of the $21^{\text {st }}$ century in traditional classroom training (Dotlich \& Noel, 1998). Action learning is a form of continuous learning and reflection, and it is a problem-based learning, that is why it seems to be a rather beneficiary practice for the individual as well as the organisation. In action learning the individual is given a problem to solve and is expected to provide a possible solution to the problem or issue. While responding to this significant problem the individual is expected to learn and develop through hands-on experience (Day, \& Halpin, 2001).

In action learning, teams or individuals conduct projects and develop a solution to a real problem within the organisation. This means that most of the time these recommendations are to be implemented to succeed. The problems are diverse and numerous while the time frame can be anywhere between a few weeks to several months. All in all, the process of action learning aims at developing cognitive and interpersonal skills of leaders, but these training activities are not applicable for developing technical skills (Yukl, 2006).

Higher education institutions in Kosovo. Higher education in Kosovo emerged in circumstances of ongoing ethnic tensions. Thus, the legacy of the past has an essential influence on their actual situation. The University of Prishtina as the oldest one was established in the academic year of 1969/1970 and had significant influence on future social and economic developments of Kosovo. Initially, it was a bilingual university serving both Albanian and Serb ethnic communities. However, the academic quality and research potential of the university were not at the highest level, because it was poorly funded and politically influenced.

In the aftermath of war, the UN Security Council (by means of Resolution 1244) placed Kosovo under international Administration that supported the building of selfgoverning institutions but without prejudice to its final political status. In this post-conflict context, Kosovo's education system has been confronted with the necessity to rebuild destroyed school facilities, reorganise staff and resources and rearrange curricula. During this period, until the establishment of the Ministry of Education, Science and Technology (MEST) in 2001, the Kosovar higher educational system was governed by the UN Administration (UNMIK), respectively by its Department of Education and Science.

With the proclamation of independence in 2008, the primary responsibility for higher education was taken by the Ministry of Education, Science, and Technology under the Law on Higher Education in Kosovo. The Law on municipalities, promulgated in June 2008, gives enhanced competencies in higher education to the lately formed municipality of North Mitrovica (Law on Local Self-government, 2008). Furthermore, the Law on Education offers a special provision for the municipality of North Mitrovica to establish the University 
of North Mitrovica as an autonomous public institution of higher education and gives the municipality the authority to exercise responsibility for this public Serbian language university. However, the most severe challenge of Kosovo's higher education system remains its low-quality standard regarding teaching methods and research activities. The politicisation of the universities and lack of academic autonomy are additional challenges of the higher education, which reflect in student achievements and their low incorporation into the labour market and economic development.

In Kosovo, higher education is provided at universities, private institutions of higher education (Bartës Privat i Arsimit të Lartë), such as colleges, research institutes, and high schools. There were initially two public universities: one based in Prishtina and one in northern Mitrovica (which at the moment is not integrated into the Kosovo education system but operates as a parallel system, funded by the Serbian government). There are other public higher education institutions in Kosovo, namely the University of Prizren, established in 2010; the University of Peja, the University of Gjakova, University of Gjilan, University of (South) Mitrovica, all established in 2012/2013; the University of Applied Science in Ferizaj; Faculty of Islamic Studies and Kosovo Academy for Public Safety.

The higher education system in Kosovo is also composed of many private higher education institutions, officially defined as colleges, gathering more than 45.000 students. Nevertheless, in comparison to these private colleges, public universities with around 75.000 students have higher academic standards, are less expensive and therefore are more credible and attractive for students.

The study involved the use of theoretical methods to analyze scientific and methodological literary sources and exploratory method to formulate research findings.

\section{RESULTS}

Kosovo established its independence only in 2008 and has ever since been subject to significant changes not only in the political sphere but every domain. The country has undergone several changes in the government policies, and young people primarily inhabit social transformations which have further led to higher education institutions fostering new approaches to learning (Grajcevci, \& Shala, 2017).

The first challenge in developing leadership skills among the staff of educational institutions in Kosovo is the presence of bureaucracy and government control. Organisations tend to handle pressure and control by becoming similar to other organisations working in the same field, a phenomenon known as 'institutional isomorphism'. Similar to what literature suggests educational institutions in Kosovo are becoming increasingly similar in their functioning and service provision. The first challenge of education institutions in Kosovo is to break free from government control.

The second challenge of educational institutions is the fact that they are strongly politicised and as such fail to function as independent bodies. These institutions do not adhere to any organisational practices. In this regard, the performance of educational institutions in Kosovo is damaged by the lack of planning. Planning is a key to any organisation, an understanding that is often at odds with postmodernism which notes that strategic planning leads to wasting resources and time because the future is uncertain and as such unpredictable. Past years have witnessed an increasing focus of governments on strategic planning among education institutions.

The lack of networking initiatives negatively influences education quality and may be partly a result of the lack of proper leadership capital within these organisations. Since 
sciendo Порівняльна професійна педагогіка 8(3)/2018

Comparative Professional Pedagogy 8(3)/2018

entirely independent education institutions no longer exist, such organisations require a high degree of cooperation among one another. Therefore, universities aim to integrate horizontally by cooperating with other national or international universities working in the same domain to create social and economic benefits. Such cooperation tends to bring benefit for all, in the form of offering teaching support and providing resources. However, at times this cooperation between institutions tends to lead to an organisation rethinking its purpose and aims (Stoten, 2011).

These collaboration networks are built on three types of collaboration, namely:

- abstract collaboration (i.e., collaboration on policies),

- strategic planning;

- professional domain (i.e., teaching).

On the other hand, the effectiveness of such collaboration has been hindered by the tendency of institutions to focus on their interests and as such limit their overall profitability. Universities today are less diverse if compared to those of the early 1990s, which can be the result of increasing government policies in finances, innovations and curriculum changes which have all contributed to the real similarity of institutions.

Finally, education institutions in Kosovo have become functional during the last ten years. Before these institutions functioned under less than ideal circumstances. These developments have contributed to higher education institutions, developed on research and academic quality, leadership and organisational culture. The existing status quo on the responsibility and role of educational institutions has contributed to the lack of leadership and management skills within universities. One of the critical challenges of higher education institutions is the lack of management skills and in particular while developing new study programs and research projects. These new initiatives embody the need for leadership and management, which demands additional funds. As such this new type of organisation represents a managerial model in responding to social issues.

\section{CONCLUSIONS}

The changing environment of higher educational institutions is not an issue limited to any country; it is instead a global challenge to which educational organisations need to adjust (Stoten, 2011). These changes have exposed teaching staff to the issue of workplace performance, observations, and ultimately professional development. The latest developments in the teaching professions (i.e., Quality Assurance, A Level Information System) have contributed to teaching staff conforming to the goals of educational organisations and complying with growing practices. Educational professionals are being urged to become leaders or followers, and as leaders, they are being taught to conform to, respect the hierarchy and take responsibility for the learning outcomes.

Therefore, more should be done in universities to promote organisational leadership development. Empowering the staff would be a beneficiary approach for every institution. Current developments in the education have proven that leadership development in universities is no longer an option, it is instead a necessity. This development takes place at the beginning of teachers' carrier and aims to assist them in developing leadership skills they need to lead schools in the future. School leaders who are considered to be successful at leading tend to make sure that their staff have access to workplace learning and training with many schools providing sets of professional learning activities which ensure the development of leadership skills.

The development of leadership that rests on organisation theory is hindered by numerous current challenges at the universities in Kosovo. These challenges are: lack of 
sciendo Порівняльна професійна педагогіка 8(3)/2018 Comparative Professional Pedagogy 8(3)/2018

networking and cooperation, lack of planning and, ultimately, the lack of management and leadership skills.

The paper elaborated approaches that could lead to effective leadership within universities. Practices such as multisource feedback, action learning and coaching have proven to be useful in education literature, and their application could increase leadership capacities of educational institutions that are built on organisational approaches and theories concerning enhancement of their quality. In our future research we are going to consider possibilities of wider use of the above mentioned practices in the universities of Kosovo.

\section{REFERENCES}

1. Atwater, L. E., \& Brett, J. F. (2005). Antecedents and consequences of reactions to 360-degree feedback. Journal of Vocational Behavior, 66 (3), 532-548.

2. Barney, J. B., \& Hansen, M. H. (1994). Trustworthiness as a source of competitive advantage. Strategic Management Journal, 15, 175-190.

3. Bass, B. (1994). Improving organizational performance through transformational leadership. Thosand Oaks, CA: Sage Publications.

4. Blanchard, K., \& Johnson, S. (2003). The One Minute Manager. New York, NY: HarperCollins. Free Press.

5. Covey, S. R. (2004). The 7 Habits of Highly Effective People. New York, NY:

6. Day, D. V. (2000). Leadership development: a review in context. Leadership Quarterly, 1, 581-613.

7. Day, D. V., \& Halpin, S. M. (2001). Leadership development: A review of best industrial practices. Alexandria: U.S. Army Research Institute for Behavioral and Social Sciences.

8. Dotlich, D. L., \& Noel, J. L. (1998). Action learning: How the world's top companies are re-creating their leaders and themselves. San Francisco, CA: Jossey-Bass.

9. Eden, D., Geller, D., Gerwitz, A., Inbar, I., Liberman, M., \& Pass, Y. (2000). Implanting Pygmalion Leadership Style through Workshop Training: Seven Field Experiments. Leadership Quarterly, 7, 171-210.

10. Estyn. (2014). Twelve secondary school Improvement Journeys. Cardiff: Estyn. Retrieved from http://www.estyn.gov.uk/english/docViewer/297105.9/twelvesecondary-schoolimprovement-journeys-december-2013/?navmap=30,163.

11. Grajcevci, A., \& Shala, A. (2017). Investigating the link between achievement goals, motivation and parent expectations in university students in Kosovo. Center for Educational Policy Studies Journal, 7 (4). Retrieved from http://www.cepsj.si/ pdfs/cepsj_7_4/pp_ 147-164.pdf.

12. Ilgen, D. R., Fisher, C. D., \&Taylor, M. S. (1979). Consequences of individual feedback on behaviour in organizations. Journal of Applied Psychology, 64, 349-371.

13. Kilburg, R. R. (1996). Toward a conceptual understanding and definition of executive coaching. Consulting Psychology Journal: Practice and Research, 48, 134-144.

14. Laabs, J. J. (1991). The global talent search. Personnel Journal, 3, 38-44.

15. Locke, E. A., \& Latham, G. P. (1990). A theory of goal setting and task performance. Englewood Cliffs, NJ: Prentice Hall.

16. London, M., \& Smither, J. W. (2002). Feedback orientation, feedback culture and the longitudinal performance management process. Human Resource Management Review, 12, 81-100. 
17. McCauley, C. D., \& Brutus, S. (1998). Management development through job experiences. Greensboro, NCL: Center for Creative Leadership.

18. McCall, M. W., Jr., Lombardo, M. M., \& Morrison, A. M. (1988). The lessons of experience: How successful executives develop on the job. New York, NY: The Free Press.

19. McKnight, G. H., Cummings, L. L., \& Cervany, N. L. (1998). Initial trust formation in new organizational relationships. Academy of Management Review, 23, 473-490.

20. Merton, R. (1948). The self-fulfilling prophecy. Antioch Review, 9, 193-210.

21. Mullins, L. (2007). Management and organizational behaviour. Edinburgh: Financial Times Prentice Hall.

22. Peterson, D. B. (1996). Executive coaching at work: The art of one-on-one change. Consulting Psychology Journal: Practice and Research, 48, 78-86.

23. Riggio, R. E. (2008). Leadership Development: the current state and future expectations. Consulting Psychology Journal: Practice and Research, 3, 383-392.

24. Shala, A., \& Grajcevci, A. (2017). Digital competencies among students' populations in Kosovo: the impact of inclusion, socioeconomic status, ethnicity and type of residence.

25. Smither, J. W., London, M., \& Reilly, R. R. (2005). Does Performance Improve Following Multisource Feedback? A Theoretical Model, Meta-Analysis, and Review of Empirical Findings. Personal Psychology, 55, 33-66.

26. Smither, J. W., London, M., \& Richmond, K. R. (2005). Relationships between leaders' personality and reactions to, and use of, multisource feedback: A longitude study. Group and Organizational Management, 30 (2), 181-210.

27. Seifert, C. F., McDonald, R. A., \& Yukl, G. (2003). Effects of Multisource Feedback and a Feedback Facilitator on the Influence Behaviour of Managers toward Subordinates. Journal of Applied Psychology, 88 (3), 561-569.

28. Yammarino, F., \& Atwater, L. (1993). Understanding self-perception accuracy: Implications for human resource management. Human Resources Management, 32, 231-247.

29. Yukl, G. (2006). Leadership in Organizations. Upper Saddle River: Pearson Prentice Hall. 